\title{
Further studies of Trichomonas vaginalis with transmission and scanning electron microscopy
}

\author{
N. M. OVČINNIKOV, V. V. DELEKTORSKIJ, E. N. TURANOVA, AND \\ G. N. YASHKOVA \\ Department of Microbiology and Gonorrhoea Unit, Central Research Institute of Skin and Venereal Diseases, \\ Ministry of Health, Moscow, USSR
}

Our knowledge of the fine structure of Trichomonas vaginalis has been considerably extended by several electron microscopic studies (Inoki and Hamada, 1953; Anderson and Beams, 1959; Ludvik, Stokłosova, and Weglarska, 1961; Perju and Petrea, 1963; Honigberg and King, 1964; Smith and Stewart, 1966; Panaitescu, Voiculescu, and Ionescu, 1971; Ovčinnikov and Delektorskij, 1969, 1973, 1974). These investigations demonstrated the need for further analysis of the ultrastructure of trichomonads. Many morphological details have not been defined and questions concerning the host cellparasite relationship remain unsolved. The life cycle, nutrition, and reproduction of trichomonads, and especially the way they phagocytose microbes in cases of mixed infection, have been insufficiently studied at the subcellular level.

The recent advances in the design of scanning electron microscopes, which produce three-dimensional images, permit the examination of intact trichomonads and their surface details. The value of this method is illustrated by the report of Nürnberger, Bartunek, and Schultze (1974), who worked with cultures of trichomonads. We have therefore undertaken a study of $T$. vaginalis using both scanning and transmission electron microscopy.

\section{Material and methods}

Material was taken directly from patients with trichomoniasis or with mixed infection (gonorrhoea plus trichomoniasis). For transmission microscopy, the material was processed as described previously (Ovičnnikov, Delektorskij, and Kosmacheva, 1974). For scanning microscopy, the material was fixed in $0.1 \mathrm{M}$ cacodylatebuffered glutaraldehyde for 30 to $40 \mathrm{~min}$., washed with $0.1 \mathrm{M}$ cacodylate buffer, and post-fixed in osmium tetroxide for 5 to $10 \mathrm{~min}$. After dehydration in a battery of alcohols, the specimen was transferred from 100 per cent. alcohol into propylene oxide and thoroughly shaken. The suspension was then placed on the microscope stage which had been covered with a thin layer of currentconducting glue. After being coated with gold, the Received for publication April 22, 1975 specimen was examined in the Cwikscan (USA) or Hitachi HHS-2 (Japan) microscope, both with $100 \AA$ resolution.

\section{Results and discussion}

A trichomonad may have one of the three main shapes: bulbous, amoeboid, or spherical. Under the scanning microscope its surface appears ruffled or creased (Figs 1, 3, 4) with numerous crater-like depressions (Fig. 2). Distinctly visible are the undulating membrane with a recurrent flagellum (Figs 1 and 3) and four free flagella which start off in a single bundle and then separate (Fig. 4). Sometimes the end of the axostyle is seen to protrude in the form of a spicule (Fig. 1).

Crater-like depressions in the surface appear to represent the initial stage in the formation of digestive vacuoles or pinocytotic vesicles. Ultrathin sections also clearly show numerous invaginations in the outer membrane (Figs 5, 6). Food particles are seen to be drawn into the larger invaginations. These findings do not support the suggestion of Nürnberger and others (1974) who interpreted these depressions as signs of degeneration.

The relationship of trichomonads to epithelial cells is peculiar. Figs 10 and 11 show an epithelial cell surrounded by several organisms. Frequently a trichomonad develops surface projections directed toward the epithelial cell in the form of long narrow strands (pseudopodia), which are bounded by two outer membranes and consist of homogeneous material devoid of any organelles (Figs 11, 12, 12a, 13). The organelles are situated in the opposite part of the organism, while the homogeneous layer contains numerous microfibrils having a contractile function. Not uncommonly the projections penetrate epithelial cytoplasm, nipping off fragments; sometimes an entire cell is captured (Fig. 10) and destroyed.

The principal mode of nutrition of $T$. vaginalis is represented by pinocytosis and phagocytosis, which may proceed in any part of the body. First an 

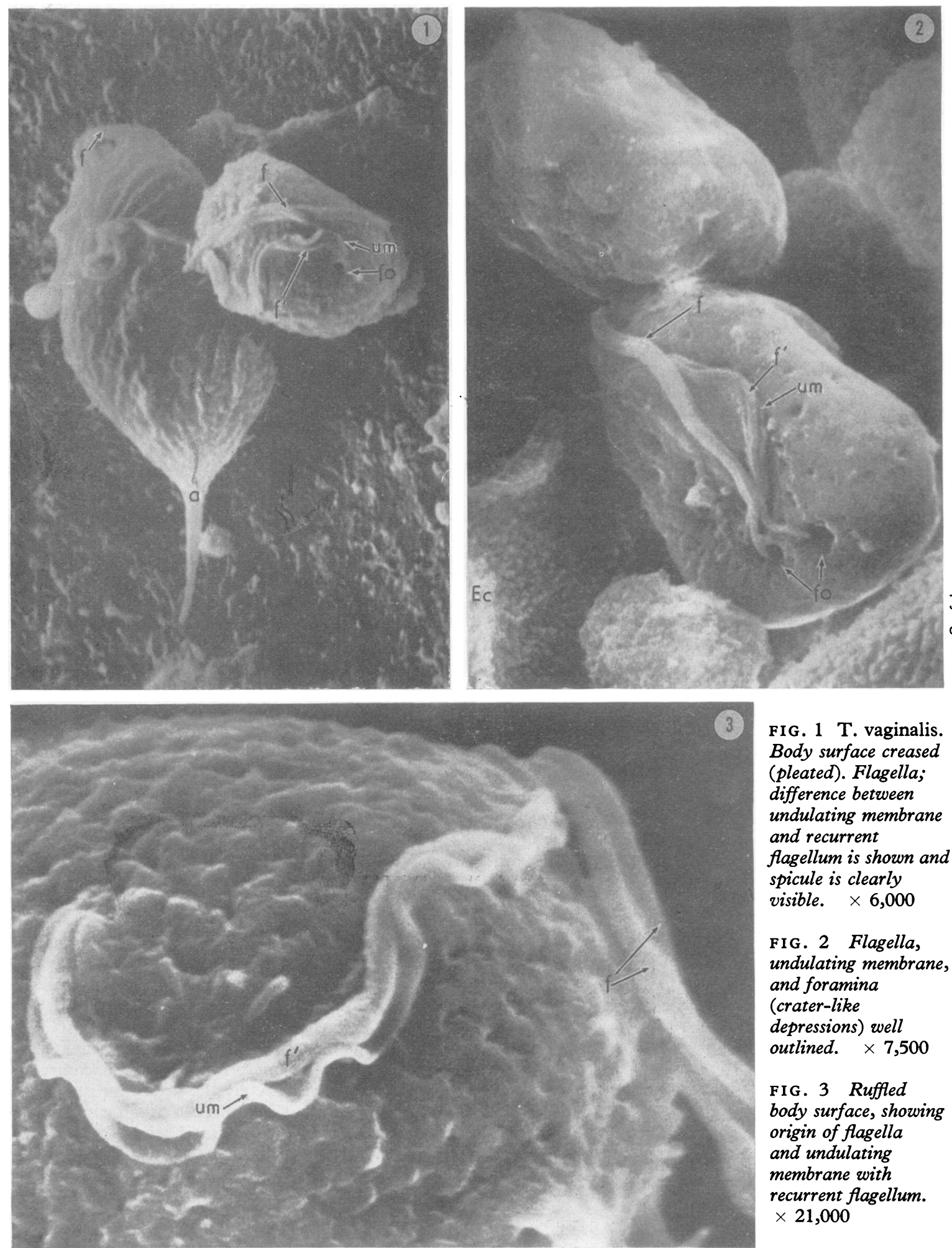

FIG. 1 T. vaginalis. Body surface creased (pleated). Flagella; difference between undulating membrane and recurrent flagellum is shown and spicule is clearly visible. $\times 6,000$

FIG. 2 Flagella, undulating membrane, and foramina (crater-like depressions) well outlined. $\quad \times 7,500$

FIG. 3 Ruffled body surface, showing origin of flagella and undulating membrane with recurrent flagellum. $\times 21,000$ 

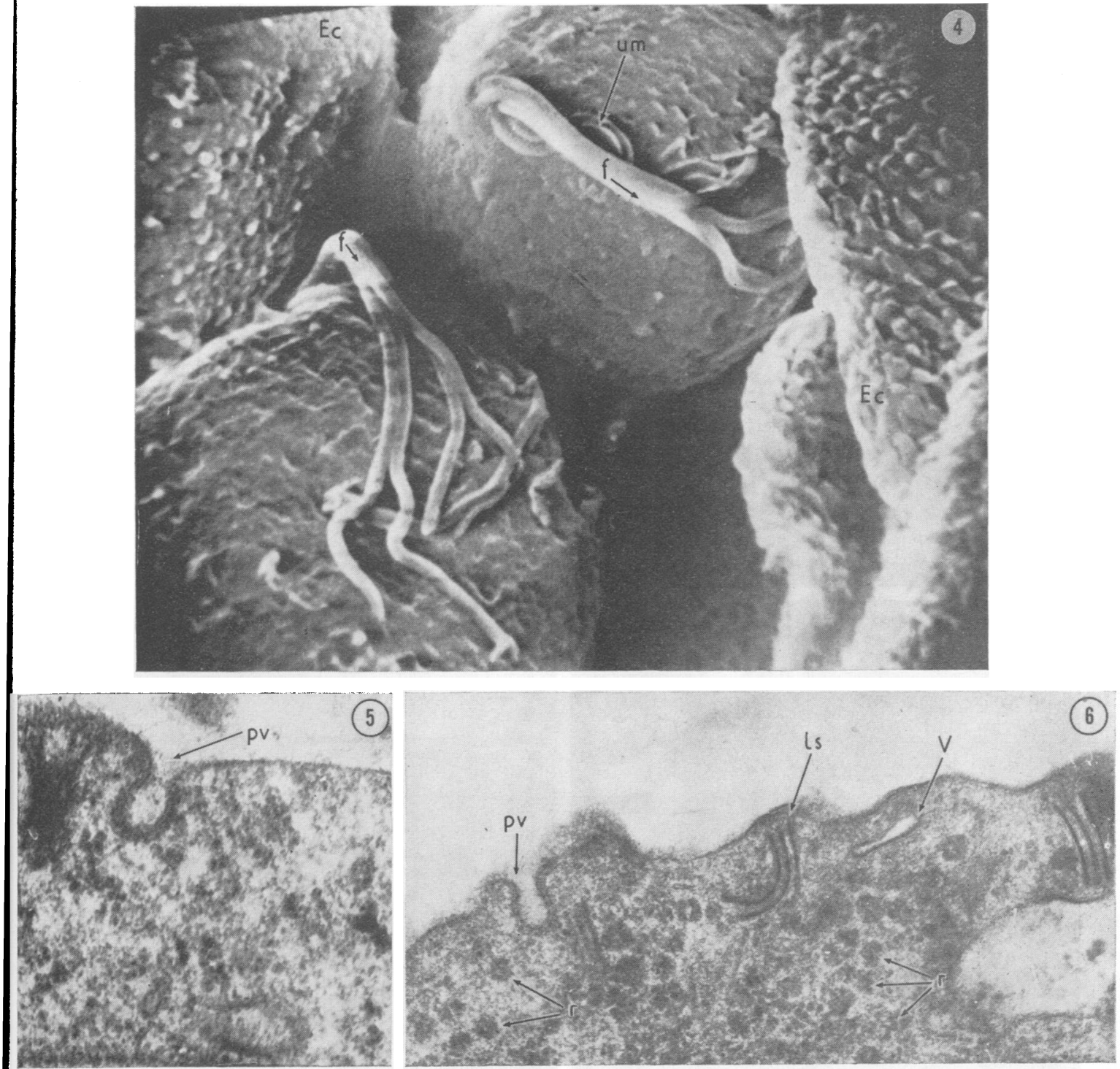

FIG. 4 Trichomonads juxtaposed to epithelial cells. $\quad \times 10,500$

FIG. 5 Pinocytotic vesicle with thickened walls in pellicule. $\quad \times 15,000$

FIG. 6 Lamellar structures arranged in parallel. Polyribosomes. $\quad \times 13,500$ 


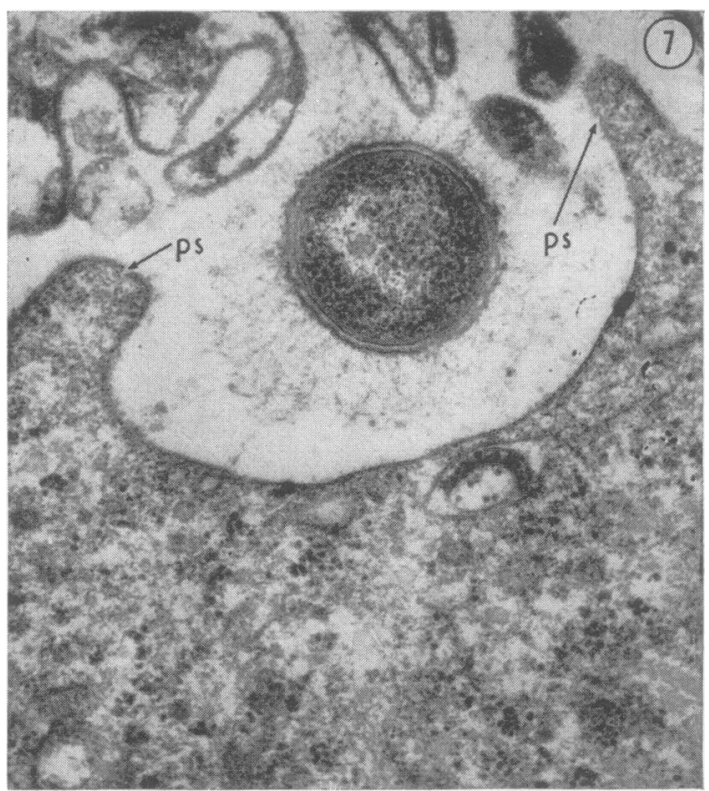

FIG. 7 Entrapment of a coccus by pseudopodia. Its structure is intact. $\quad \times 15,000$

FIGS 8, 9 Entrapment of a coccus shown in two stages.

In Fig. 8 the coccus is almost trapped. $\times 7,500$

In Fig. 9 a phagosome has formed, but the

structure of the coccus remains intact. $\quad \times 16,500$
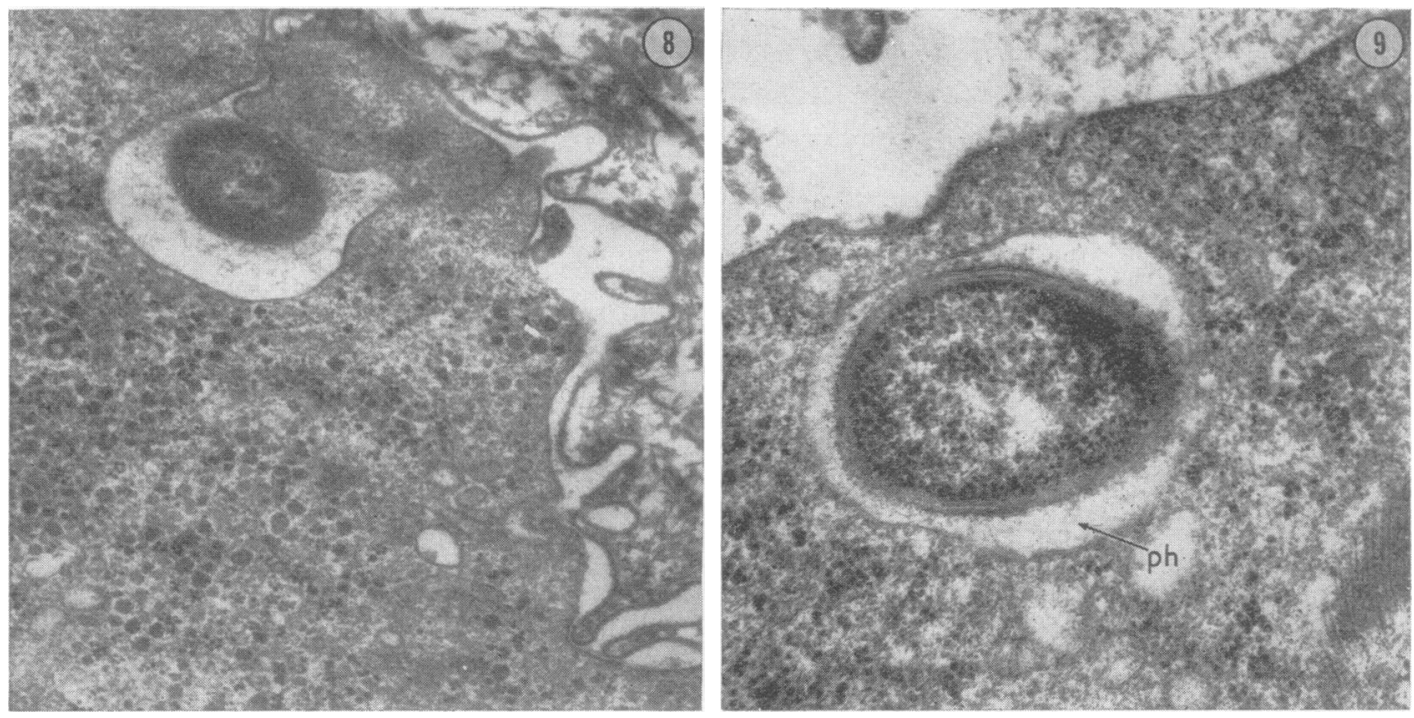

$8 \overrightarrow{0}$

융 ज़

훌. 


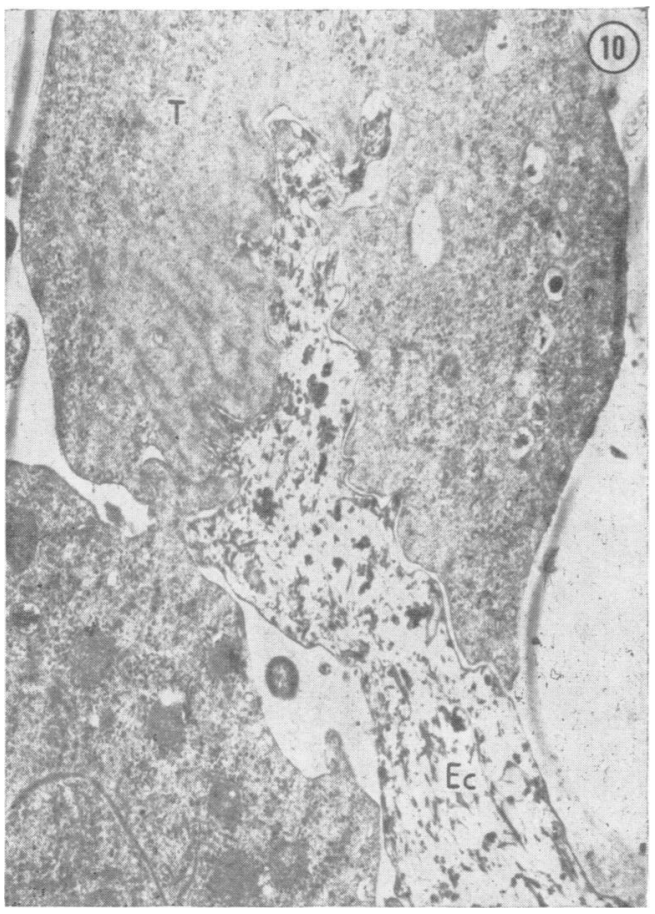

FIG. 10 Engulfment of an epithelial

cell. $\times 4,500$

FIG. 11 Trichomonads have surrounded an epithelial cell. Pseudopodia have formed. Next to the epithelial cell, the cytoplasm of the protozoon contains no organelles; these are concentrated on the opposite sides of the bodies. $\times 5,000$

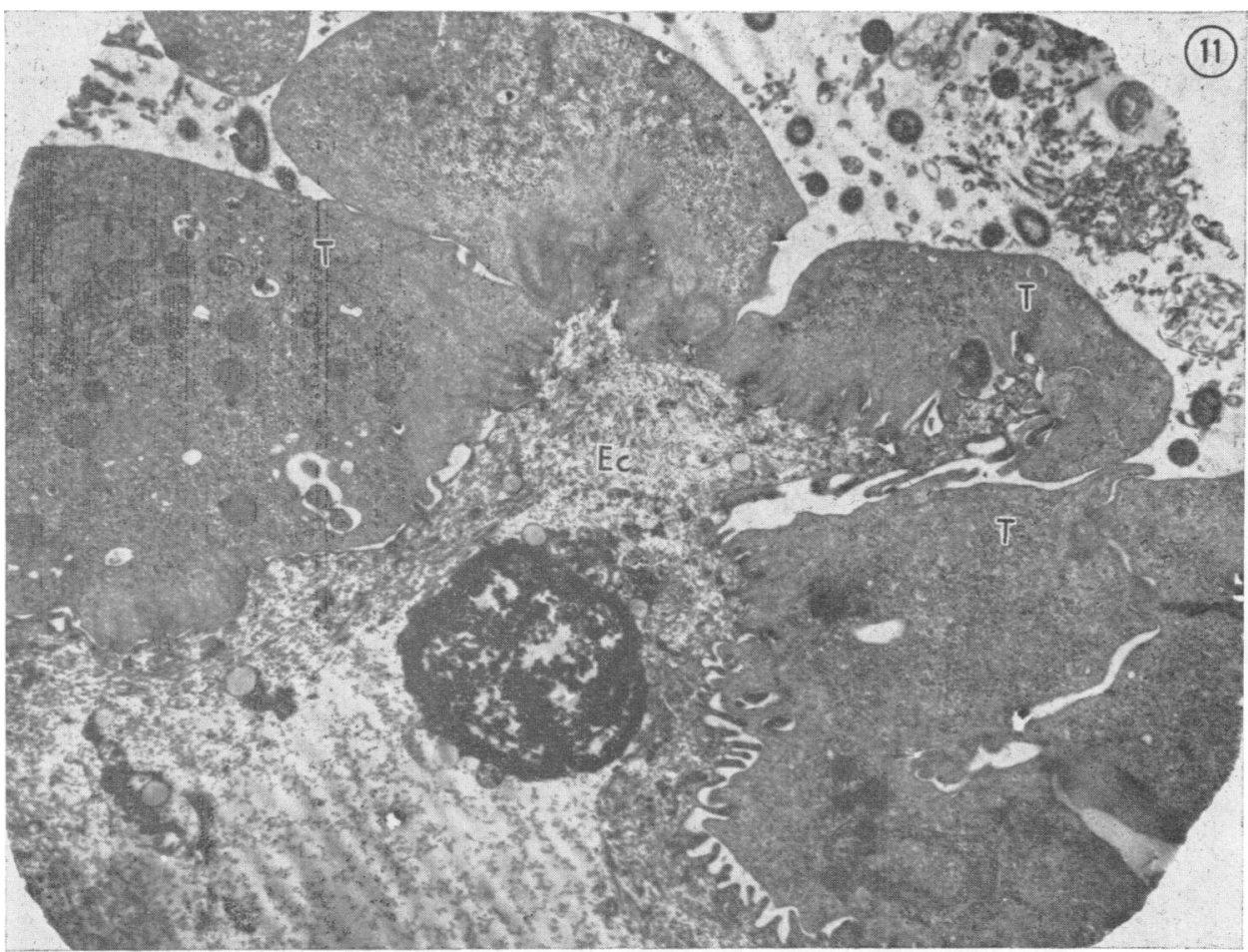




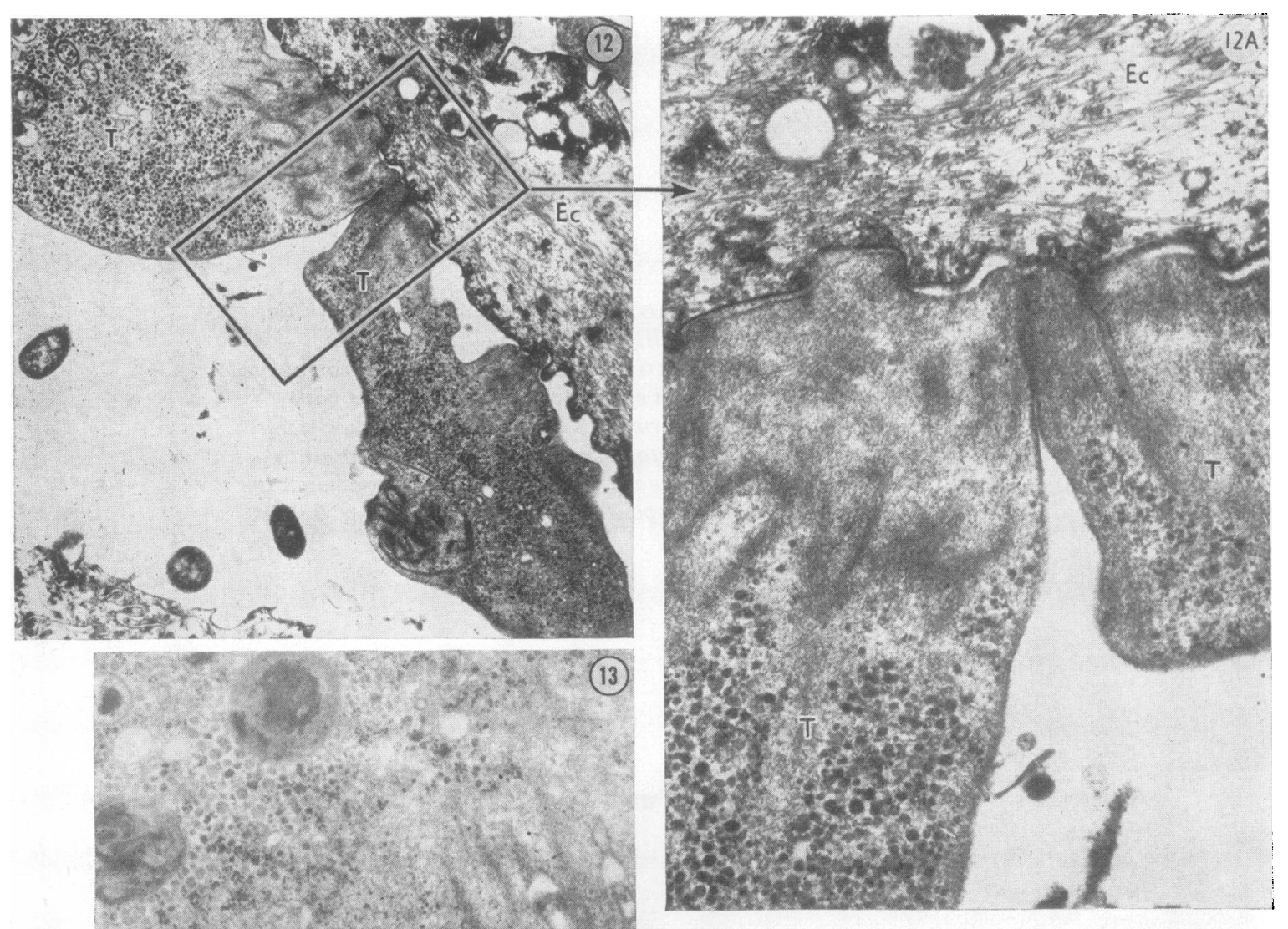

FI GS 12, $12 a$ (detail), 13 Amoeboid forms.

Pseudopodia clearly shown. $\times 4,000 ; \times 16,600$; $\times 10,000$ 
invagination appears in the cytoplasm (Figs 5 and 6 ), and gradually its edges are drawn together. The wall of the vesicle thickens and acquires a villous pattern. Micro-organisms and large particles are usually caught by pseudopodia (Fig. 7). The engulfment of a microbe is well illustrated in Figs 8 and 9. The entrapped particle may undergo digestion. Large and small particles, including entire cells, may be engulfed.

The fate of the phagocytosed micro-organisms is of interest. Electron micrographs showing entrapped diplococci and rod-shaped bacteria have already been shown in our previous report (Ovčinnikov and others, 1974). Some, but not all, organisms seem to be altered; however, we cannot say whether they have undergone changes after engulfment or have been phagocytosed in a poor condition. They are usually located in phagosomes but may lie freely in the cytoplasm with no evidence of a limiting membrane. These observations suggest a number of questions:

(1) Phagocytosis of organisms, such as the Döderlein bacillus, has adverse effects, since it disturbs vaginal $\mathrm{pH}$ and interferes with the barrier function of the epithelium.

(2) If the entrapped organisms are not destroyed but survive within trichomonads, the latter may be considered as a reservoir of infection creating additional difficulties during treatment. Thus, a strain of pathogens, such as gonococci, may be sensitive to penicillin, but trichomonads are penicillinresistant and the gonococci contained within them are probably protected from the action of the antibiotic. The release of engulfed gonococci probably follows the death of the protozoon or the multiplication of organisms within a phagosome causing its rupture.

The problem of the phagocytosis of pathogens by $T$. vaginalis is especially important when gonococcal or staphylococcal disease is also present. Mixed infections with trichomonads and gonococci are prevalent. Thus, according to Turanova (unpublished data), trichomoniasis may be found in as many as $\mathbf{7 0}$ to $\mathbf{8 0}$ per cent. of cases of gonorrhoea. Probably treatment of both diseases should be combined and the therapy of gonorrhoea should precede or accompany that of trichomoniasis. This matter deserves study as many recurrences of gonorrhoea may be due to ineffective treatment of mixed infection.

The main structural features of trichomonads have been described in a number of reports. This paper presents additional information, which supports and extends previous data and prompts a reconsideration of certain earlier theories.

In particular, it is necessary to amplify the current concepts of the morphology and functional significance of vesicles. Panaitescu and others (1971) confirmed the observations of Perju and Petrea
(1963) and Smith and Stewart (1966), who found three types of vesicles in trichomonads: vacuolated, replete, and containing filaments (lamellae).

Figs 14-24 illustrate variations in morphology and the probable functional significance of vesicles. Some of them appear typical of phagosomes or digestive vacuoles (Figs 17, 18, 20). These have a three-layered membrane (two electron dense layers and one transparent layer) and contain residues of digested food particles (Fig. 18) or micro-organisms (Fig. 9). The formation of a phagosome and fusion with a granule are well shown in Fig. 17. Phagosomes may occasionally attain huge dimensions.

Besides phagosomes, we have seen membranelimited round formations varying in size and electron density (Figs 34 and 35), as well as less compact lysosome-like structures devoid of a membrane (Figs 21-24; 41). Another type is represented by membrane-bound transparent vesicles (Figs 21 and 34). Some transparent vesicles have thick walls with a villous pattern (Figs 14-16; 36). Finally, numerous electron dense granules of different sizes (including very large ones) are distributed throughout the cytoplasm (Figs 21 and 23). In the peripheral parts of the cell, the cytoplasm has a a finely granular or fibrillar structure. After staining with Ruthenium red for acid mucopolysaccharides (Hashimoto, 1964), the reaction products are distributed peripherally in a finely granular or amorphous layer adjacent to the outer membrane and especially distinct at the walls of some vesicles (Figs 17 and 19). Thus, the existing descriptions of vesicles need revision for they are morphologically and functionally heterogeneous.

Histochemical and biochemical techniques should be valuable in the study of the metabolism of trichomonads. Some of these methods were used by Müller (1973) and Lindmark and Müller (1973), who investigated the subcellular localization of hydrolases, dehydrogenases, and catalases in Trichomonas foetus. Their observations are extremely interesting, although the functional and enzymological data for $T$. foetus probably do not apply to $T$. vaginalis, since the two species are morphologically dissimilar. Lindmark and Müller (1973) suggested the name "hydrogenosomes" for lysosome-like structures lacking hydrolases. The authors share the opinion of Heath (1974) that the functional significance of lysosomes and vesicles in trichomonads is not at all clear and requires further study. Ultrathin sections of trichomonads clearly show the outer membrane (pellicle), the nucleus and nucleolus, the parabasal apparatus, the Golgi zone, flagella, blepharoplasts, costae, and the axostyle. $T$. vaginalis has a threelayered outer membrane (Fig. 32) which adheres to the cytoplasm and continues on to the flagella and undulating membrane (Figs 39 and 40). The nucleus has a finely granular structure (Fig. 26) and contains an electron dense nucleolus. The nuclear 

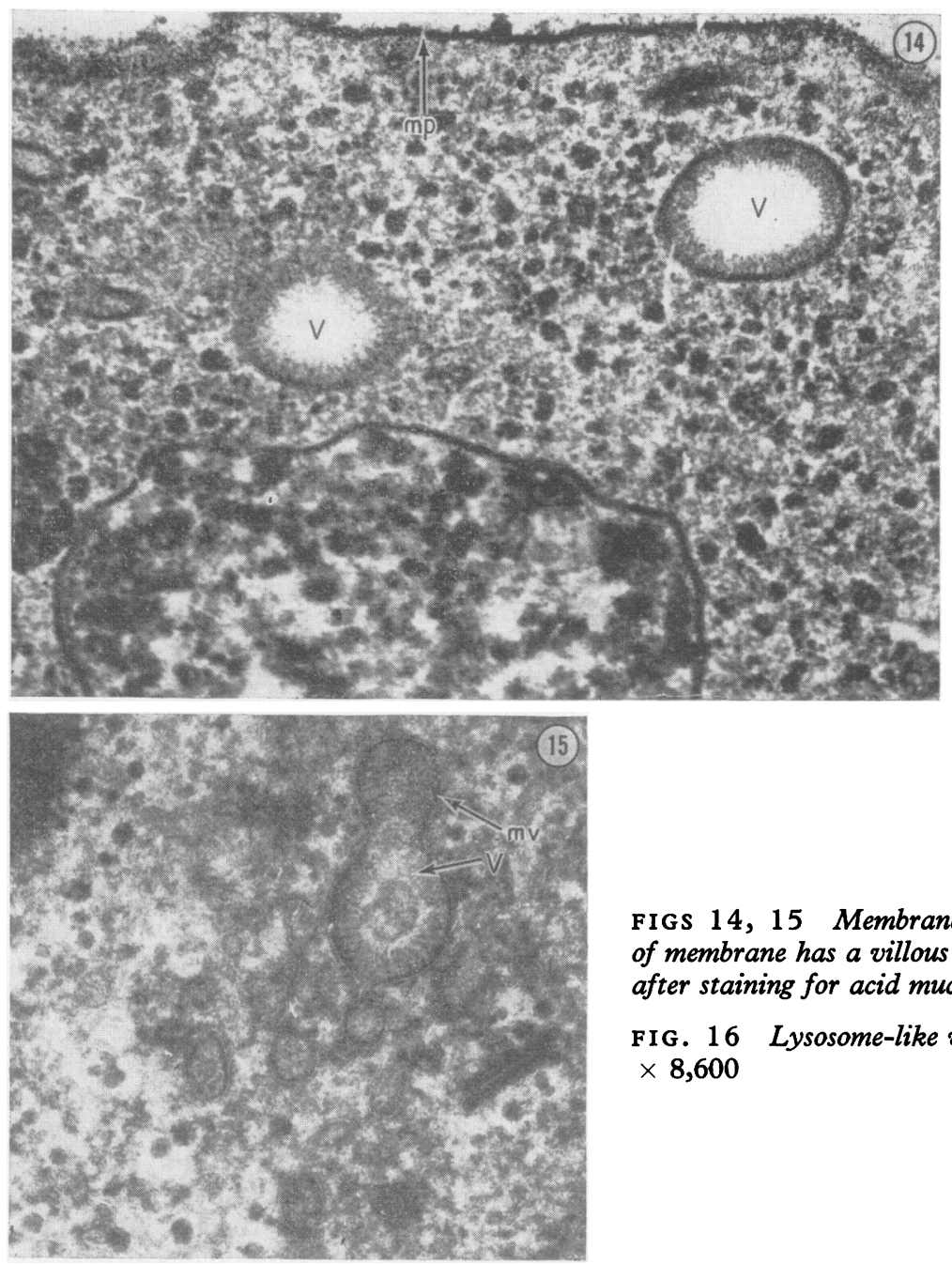

FIGS 14, 15 Membrane-bound vesicles. Inner part of membrane has a villous structure. Fig. 14 taken after staining for acid mucopolysaccharides. $\times 32,000$

FIG. 16 Lysosome-like vesicles (hydrogenosomes). $\times 8,600$

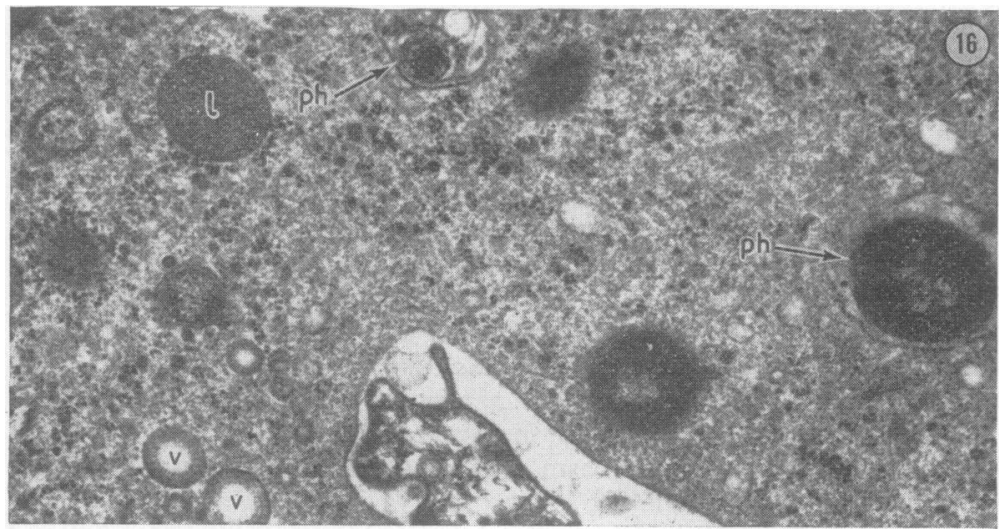



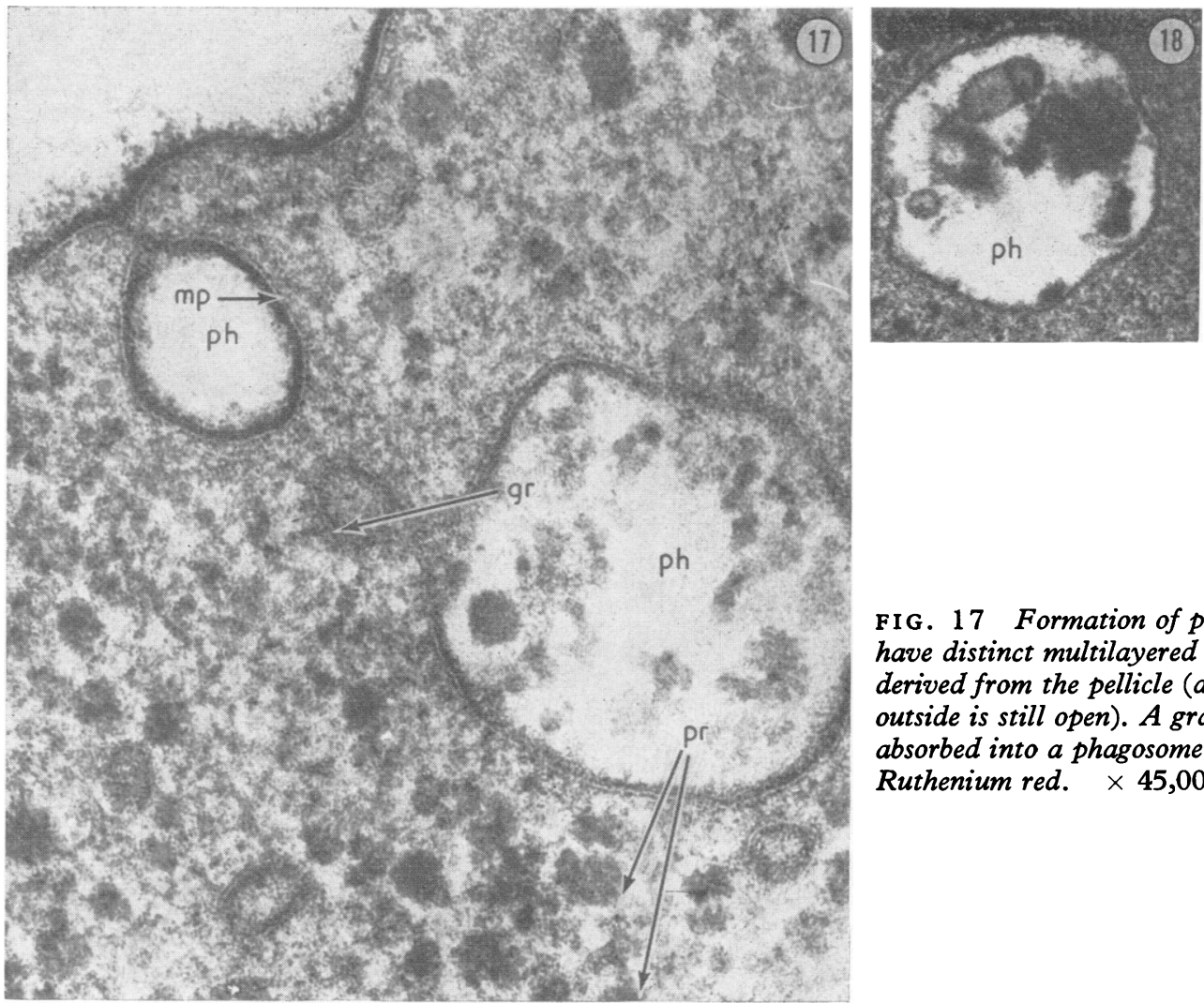

FIG. 17 Formation of phagosomes. They have distinct multilayered walls obviously derived from the pellicle (a channel leading outside is still open). A granule is being absorbed into a phagosome. Stained with Ruthenium red. $\quad \times 45,000$
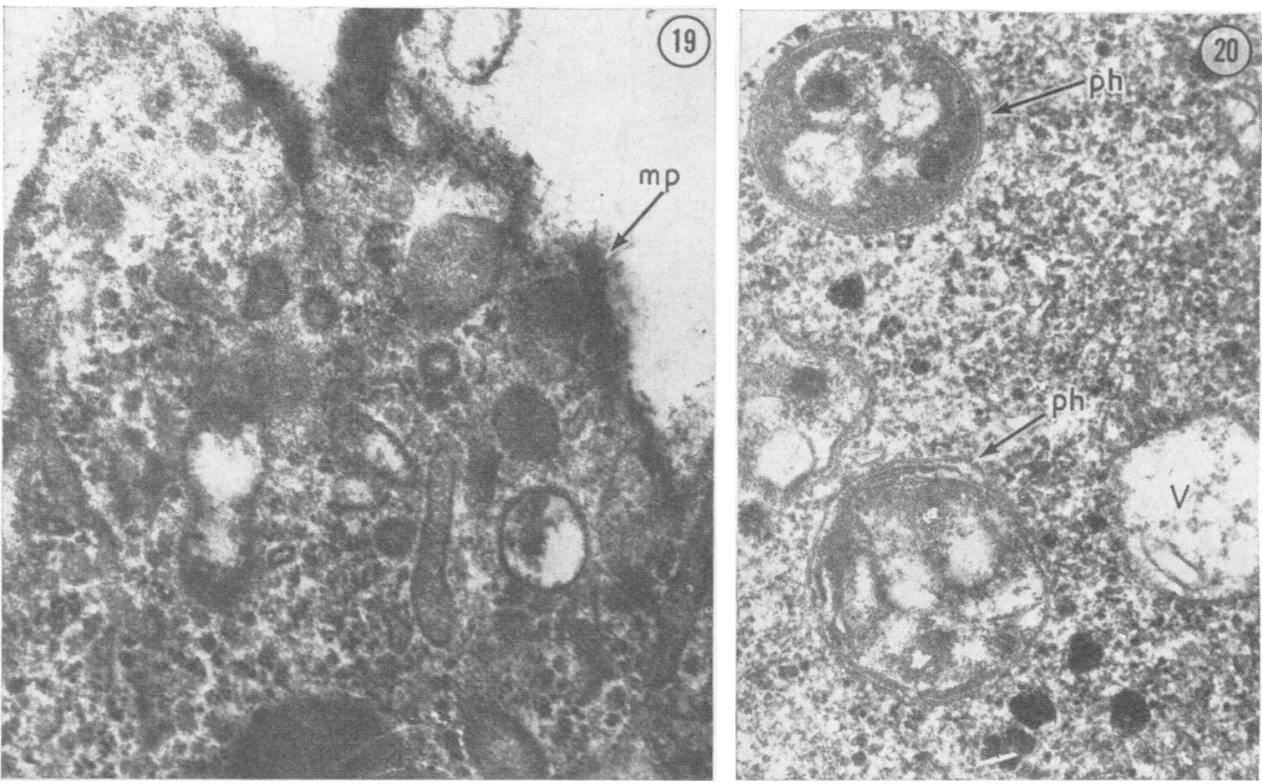

FIGS 18, 19, 20 Vesicles with multi-layered membranes and residues of digested particles (phagosomes or digestive vacuoles). Fig. 19 taken after staining for acid mucopolysaccharides. $\quad \times 30,000 ; \times 11,250 ; \times 18,750$ 

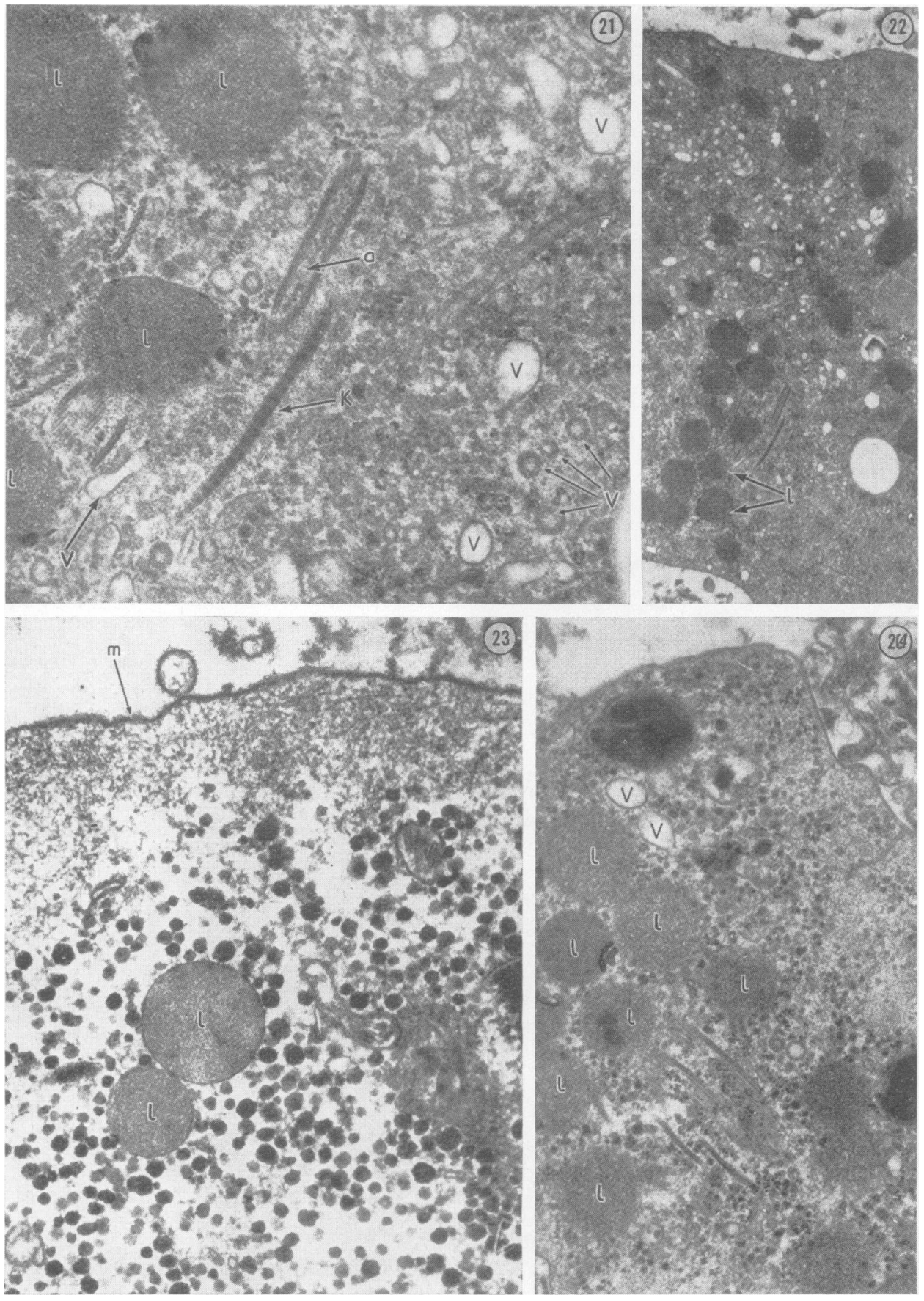

FIGS 21, 22, 23, 24 Lysosome-like vesicles

reaction products deposited at the body wall, walls of (hydrogenosomes) with or without membranes. Fig. 23 taken after staining for acid mucopolysaccharides; vesicles, and granules. $\times 20,000 ; \times 6,600$; $\times 16,600 ; \times 13,300$ 

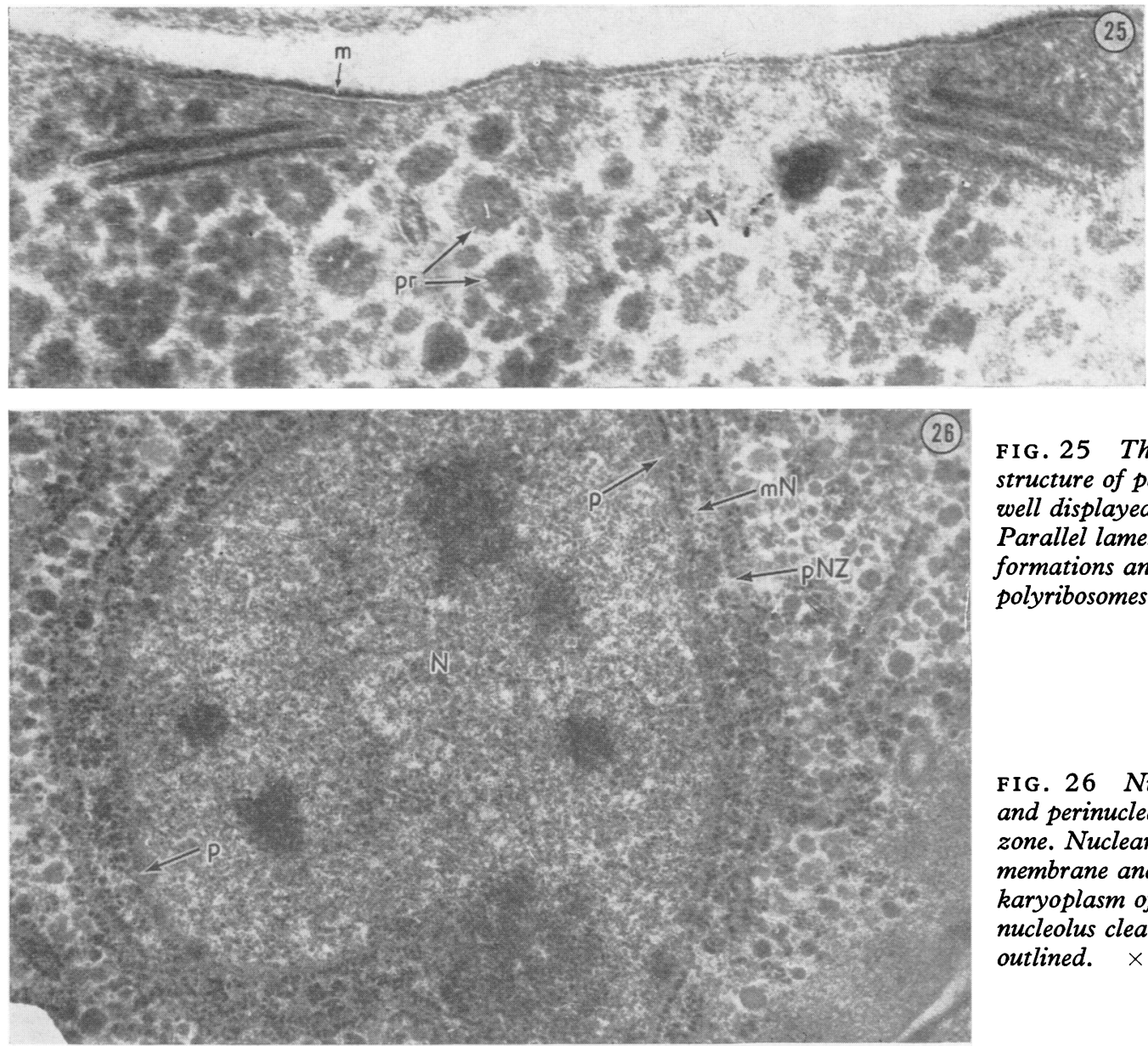

FIG. 25 Three-layered structure of pellicule well displayed.

Parallel lamellar formations and polyribosomes.

FIG. 26 Nucleus and perinuclear zone. Nuclear membrane and karyoplasm of a nucleolus clearly outlined. $\times 16,600$

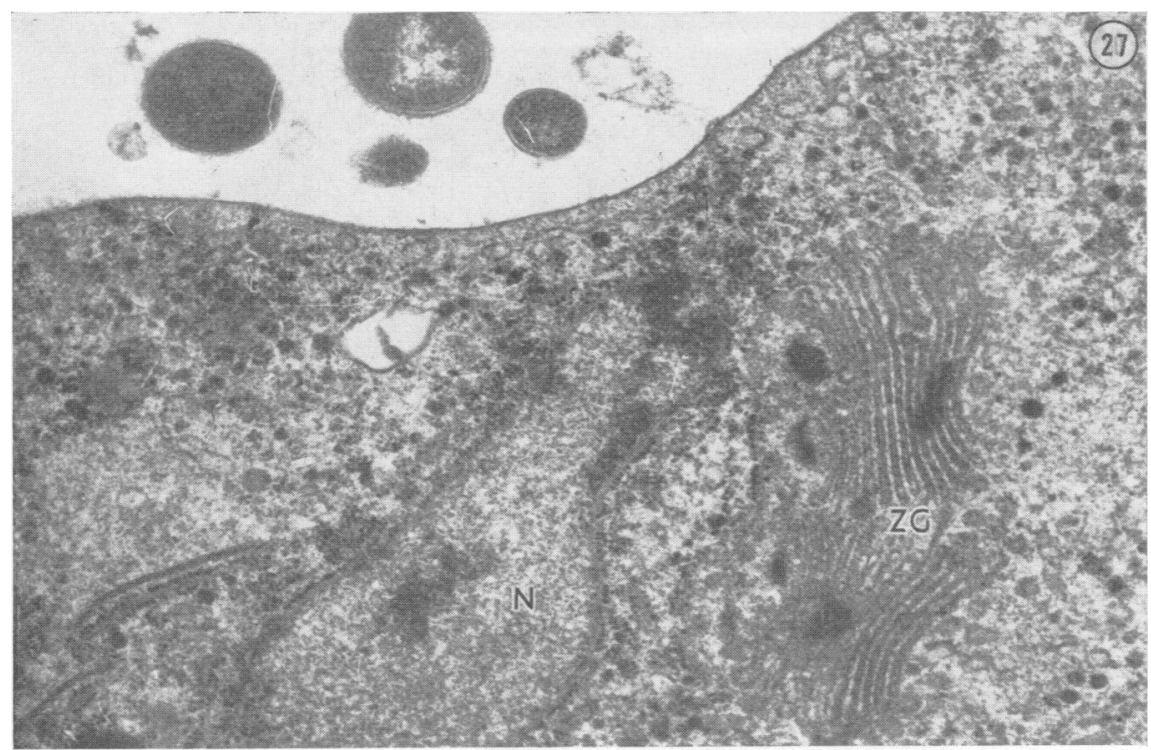

FIG. 27 Golgi zone. $\times 10,000$

융

잉

ֻे

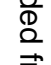

혹

룽

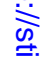

훙

ㅇํㄹ 

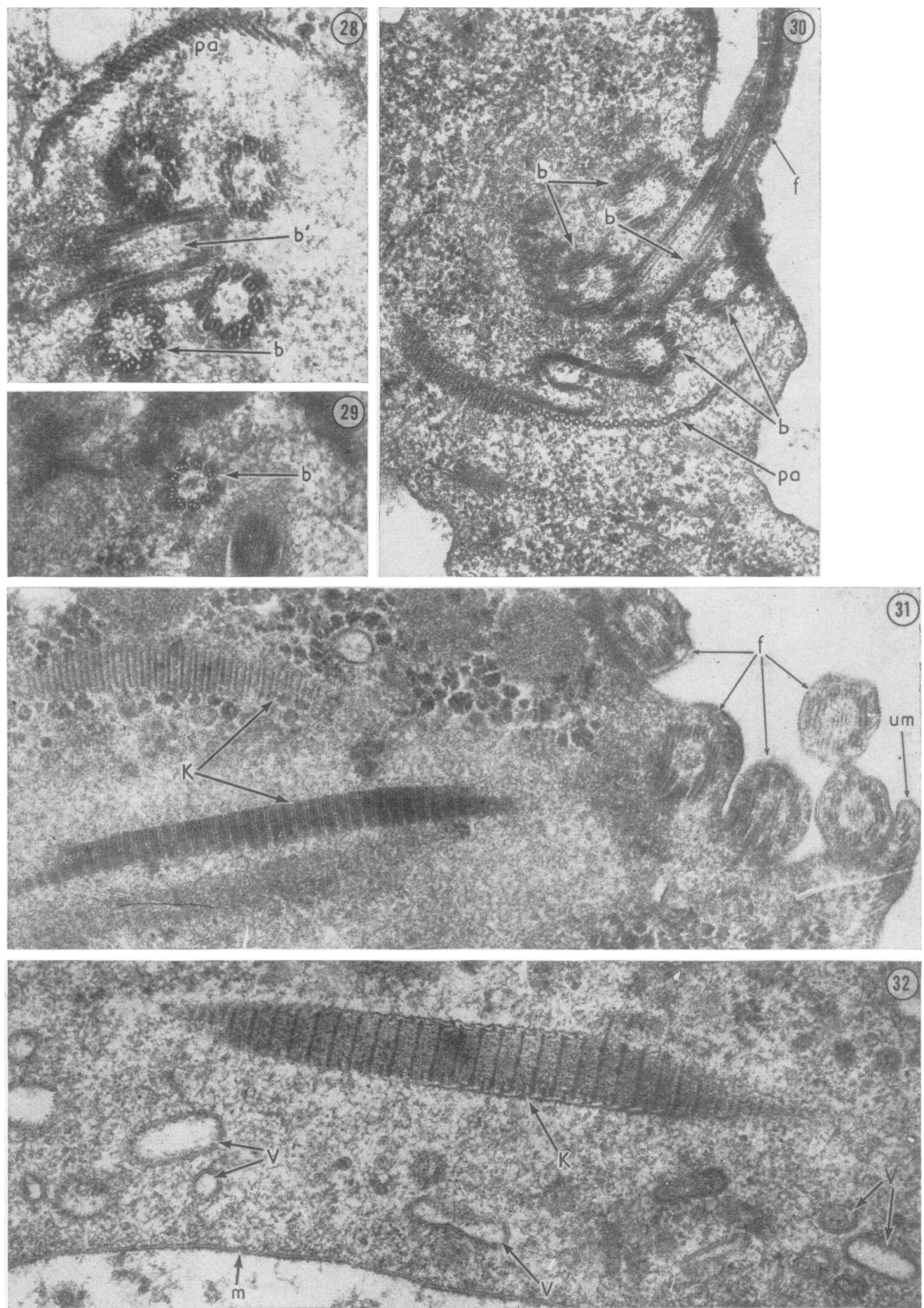

FIG. 28 Blepharoplasts cut across and obliquely. Parabasal apparatus. $\quad \times 37,750$

FIG. 29 Triplets of microtubules forming a blepharoplast. There are no central fibrils. $\times 20,000$ FIG. 30 Blepharoplasts, parabasal apparatus, and a flagellum. $\times 20,000$
FIG. 31 Costae. $\times 26,600$

FIG. 32 Structure of costa. Clear vesicles with thick membranes. Three-layered structure of pellicule. $\times 33,350$ 
membrane, with its pores, and the perinuclear zone, with electron dense granules (ribosomes), are clearly visible.

The parabasal apparatus (Figs $28,30,38$ ) is a system of tubules or ringlets (depending on the plane of section), which extends from the anterior end of the organism carrying flagella, and curves around the nucleus.

The prominent Golgi zone (Fig. 27) shows flattened sacs and vesicles with homogeneous contents of moderate electron density. In crosssection, a flagellum has nine pairs of peripheral ringlets (microtubules) and two separate ringlets in the centre (Fig. 39). It is bounded by an outer membrane. The intracellular part of the flagellum has no envelope. Each flagellum is attached to a blepharoplast. In longitudinal section, an electron dense granule marks the transitional zone between the central microtubules and the blepharoplast (Fig. 30).

Each blepharoplast consists of nine triplets of microtubules arranged in the form of a cylinder (Figs 28 and 29). In contrast to the flagellum, it has no central microtubules.

A costa extends from each of the blepharoplasts (Figs 31 and 32). The undulating membrane is also provided with a costa, which appears to join the recurrent flagellum. The costae have a specific structure resembling collagen fibres, with distinct and regular longitudinal and cross striations. They are evidently involved in the movements of the protozoon.

The axostyle is a cylindrical structure slightly tapering towards each end (Fig. 33). Its lower end often protrudes from the cell surface in the form of a spicule of variable length (Figs 1, 34, 34a). The walls of the axostyle are composed of microtubules and its internal cavity contains small inclusions.

In ultrathin sections, the undulating membrane appears as an elongated tube with a rounded end. Its length varies. In certain planes of section the impression is given that there are two or three undulating membranes (Fig. 35 and $35 a$ ), sometimes with a pinocytic vesicle (Fig. 35). A few sections show the undulating membrane within a large cavity (Figs 36 and 37), which contains food particles (Fig. 37). Possibly this is rudimentary cytostome. Clear cavities may be visualized at the base of the undulating membrane (Fig. 38), which is bounded by the pellicule (Fig. 40) continuing directly from the cell body. A spiral structure courses throughout the undulating membrane (Figs 37 and 39), and electron dense triangular formations are visible under the inner layer of the pellicle (Fig 40).

The undulating membrane is always associated with a recurrent flagellum, which is similar in structure to the other flagella. As a rule, it is seen in cross-section.
The body of a trichonomad may contain latticelike structures with a definite period (crystalloids), usually situated at the base of the undulating membrane (Figs 41 and 42). More superficially, electron dense lamellar structures are arranged in parallel (Figs 6 and 25). They may be straight or curved ; sometimes there are signs of a membrane. The significance of these two types of formation remains unclear.

Typical amoeboid trichomonads are shown in Figs 10-13, 43 and 45, and a spherical one in Fig. 44. Spherical forms are encountered mostly in an unfavourable environment or as a result of budding, for trichomonads can reproduce by budding (Figs 45 and 46 ) as well as by division.

Further attempts to elucidate the ultrastructure of $T$. vaginalis are needed, especially studies of the functional significance of some of the newly discovered morphological features. Besides electron microscopy, histochemical and biochemical methods appear to be necessary.

\section{Conclusions}

(1) Scanning electron microscopy of $T$. vaginalis has revealed the following features: a creased cell surface with crater-like depressions, an undulating membrane with a recurrent flagellum, a bundle of flagella at the anterior end of the organism, and a spicule at the posterior end.

(2) Studies of ultrathin sections have shown:

(a) High phagocytic activity, especially in amoeboid forms;

(b) Endocytobiosis of bacteria, both Gramnegative and Gram-positive;

(c) The presence of lamellar structures in the cortical layer, lattice-like structures (crystalloids) at the base of the undulating membrane, and vesicles of various types. The functions of these newly detected formations remain unclear;

(d) Phagocytosis and pinocytosis are the main modes of nutrition, but the existence of a cytostome, perhaps in a rudimentary form, can not be excluded;

(e) The relationship of trichomonads to epithelial cells may be interpreted as phagocytosis rather than fixation on to the epithelium;

( $f$ ) Mitochondria have not been found;

(g) Judging from the structure of costae and their connections with blepharoplasts, they are a part of the motor apparatus.

(3) Since trichomonads are capable of phagocytosing gonococci, they may possible serve as a reservoir of gonococcal infection and a cause of recurrences.

(4) The ability of the gonococcus to survive and multiply within the phagosomes of trichomonads, 

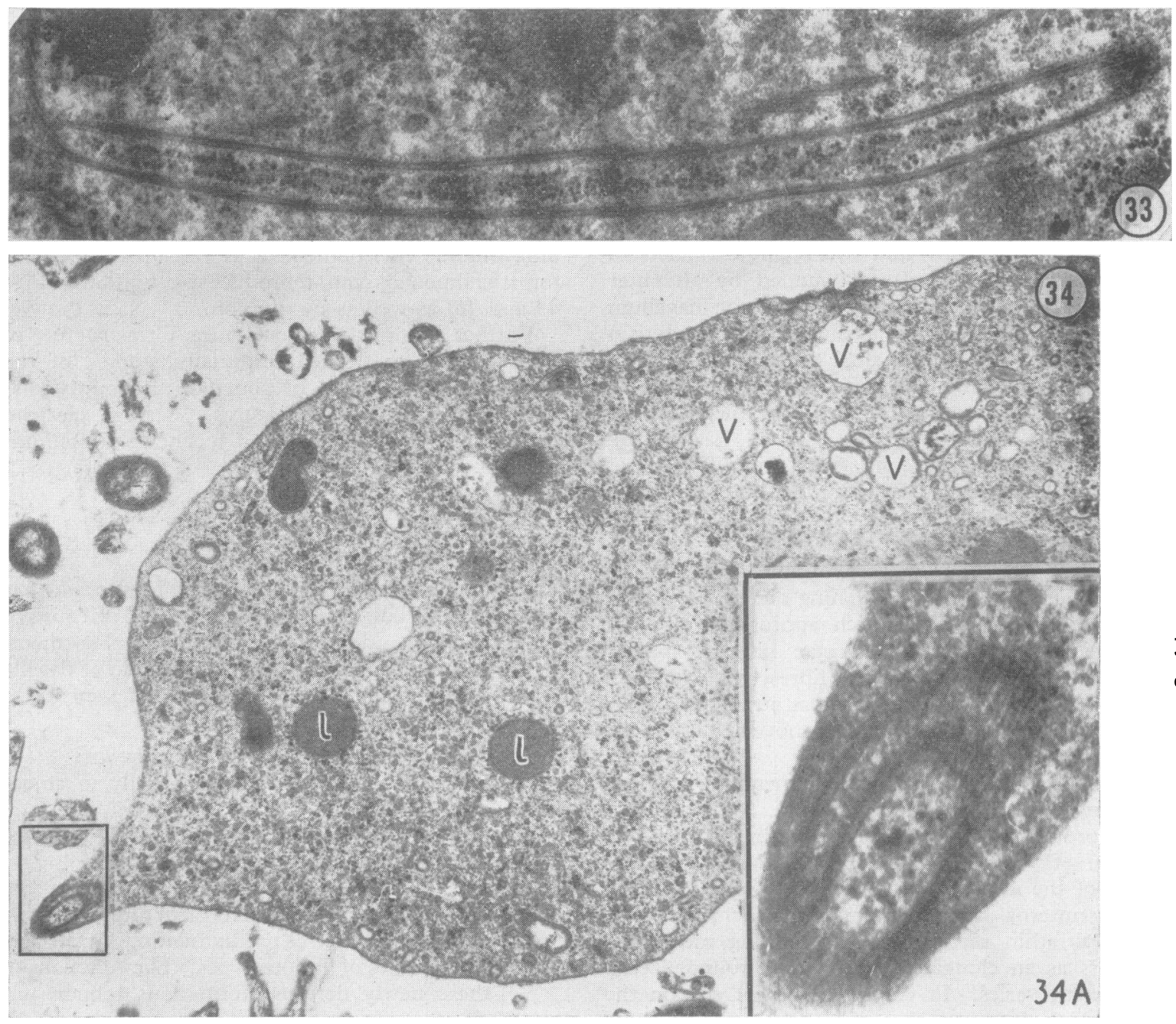

FIG. 33 Axostyle. Its walls are formed by microtubules, and it contains fine granules arranged in two longitudinal rows. $\quad \times 30,000$
FI . 34 Axostyle protruding at posterior end of a trichomonad. $\times 8,000$

FIG. 34A (detail) Axostyle in oblique section. Two rows of microtubules encircle granular contents. $\times 50,000$ 

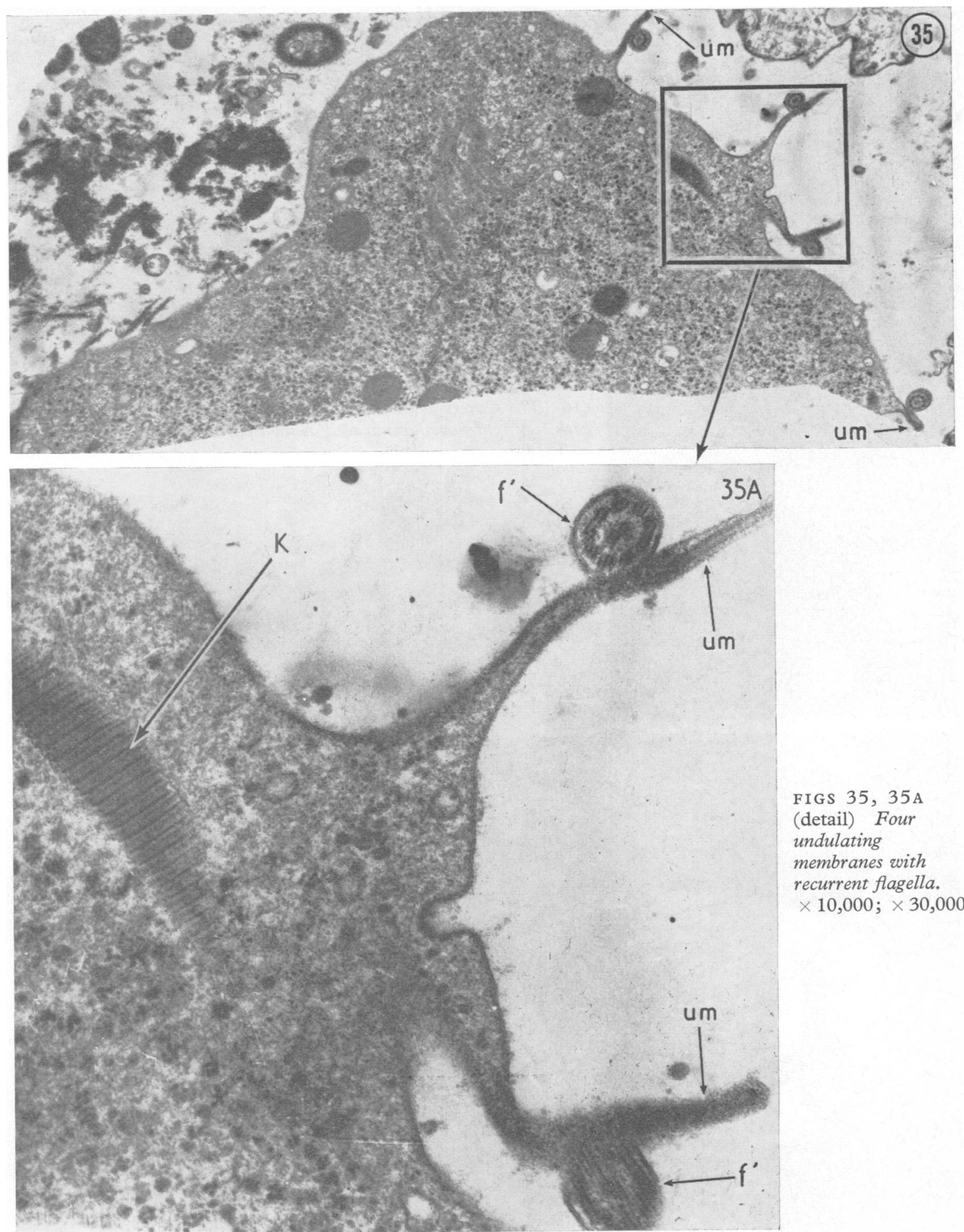

FIGS $35,35 \mathrm{~A}$

(detail) Four

undulating

membranes with

recurrent flagella.

$\times 10,000 ; \times 30,000$ 


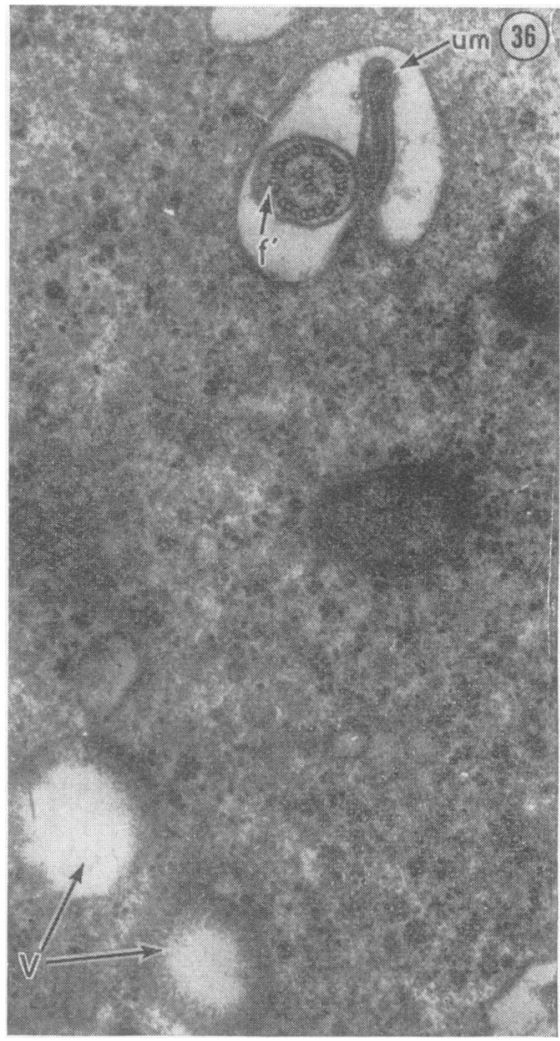

FIG. 36 Undulating membrane with recurrent flagellum in a cavity. $\quad \times 22,500$

FIG. 37 Cavity containing undulating membrane with recurrent flagellum, as well as food particles. $\times 15,000$

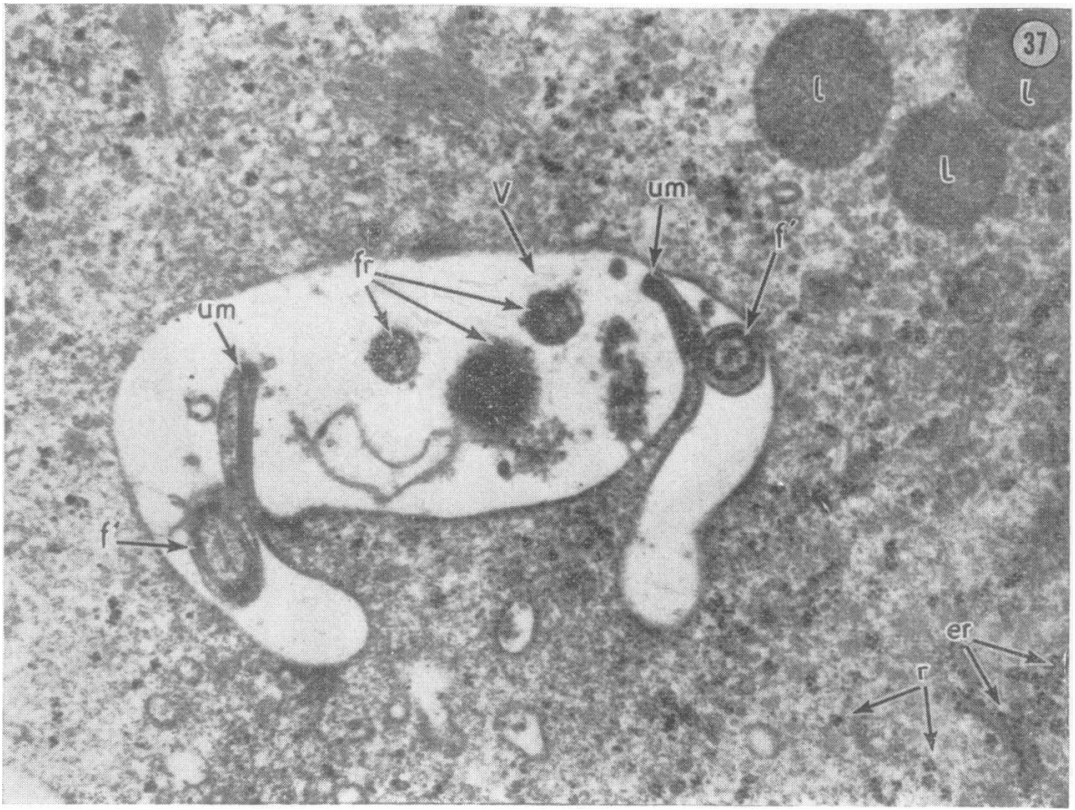




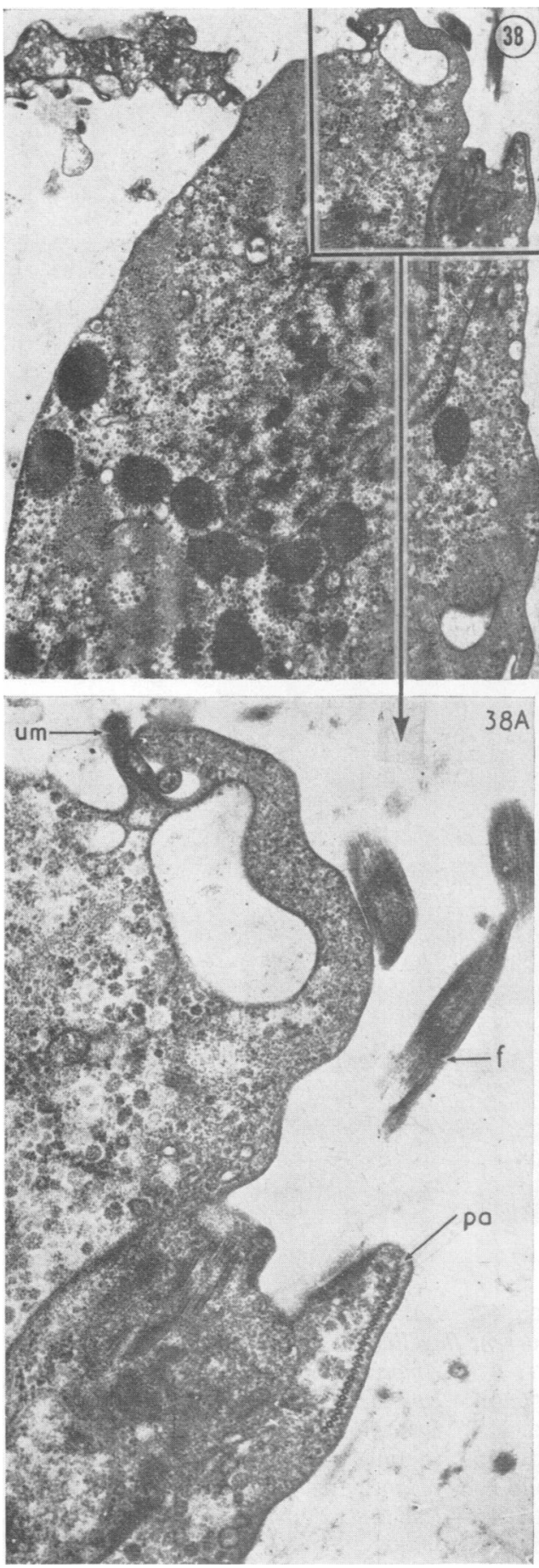

FIGS 38, 38 A (detail) Large bleb at base of undulating membrane. $\times 4,500 ; \times 13,500$ FI G. 39 Three-layered pellicule continues directly on to the undulating membrane. The structure of a flagellum is demonstrated. $\times 60,000$
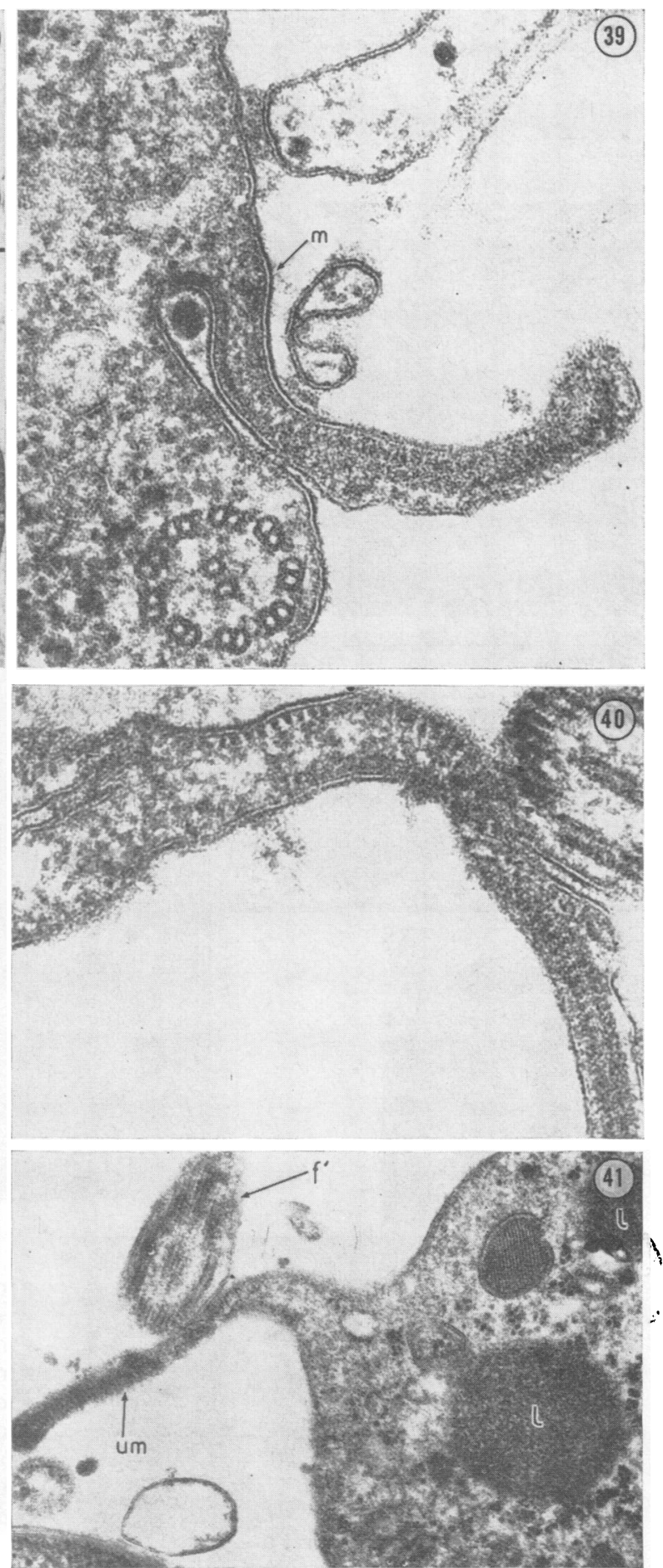

FIG. 40 Undulating membrane. Triangular electron dense formations under inner layer of pellicle. $\times 60,000$

FIG. 41 Membrane-bound lattice-like formations (crystalloids) at base of undulating membrane. $\times 30,000$ 

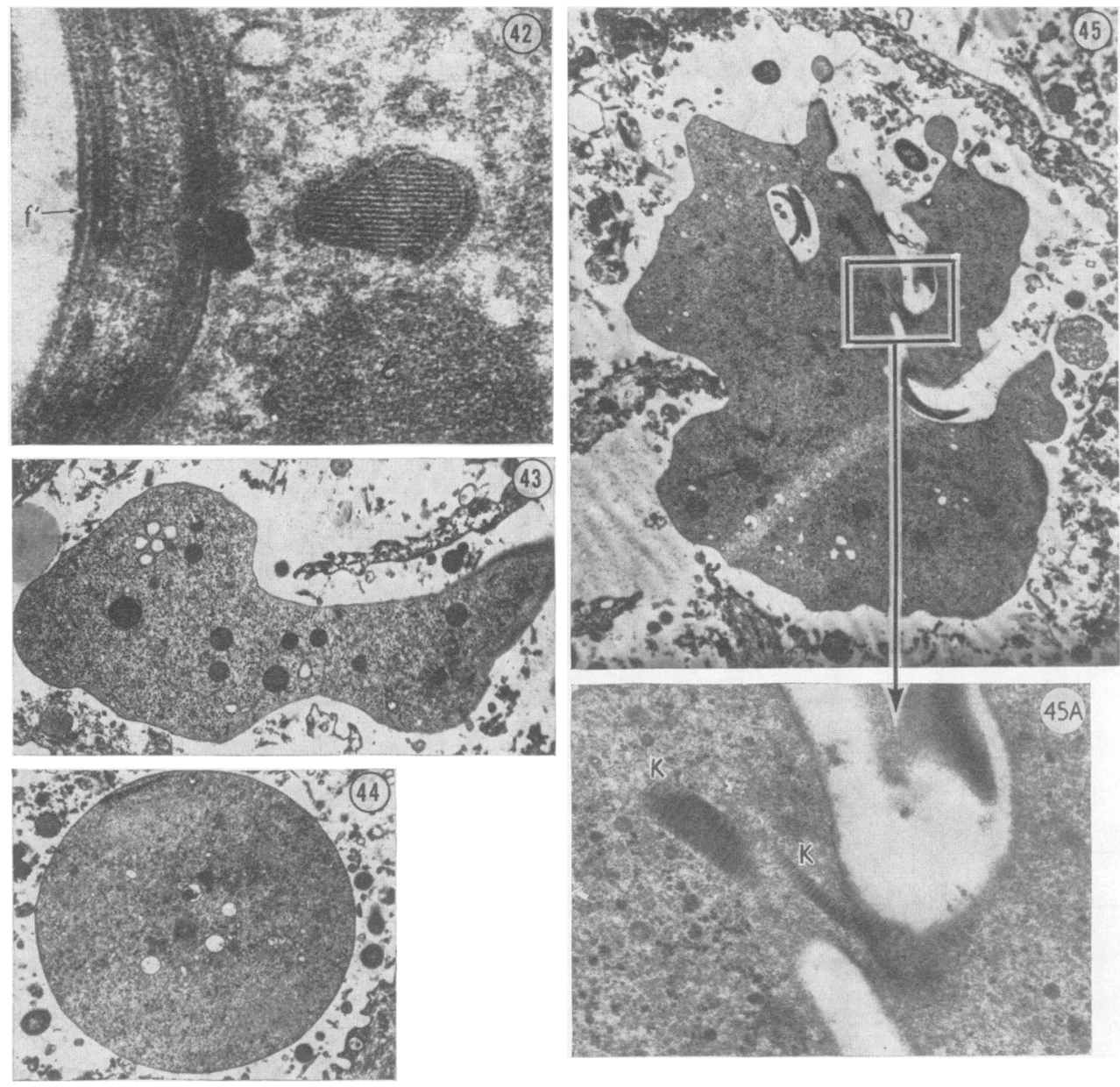

FIG. 42 Lattice-like formation under a recurrent flagellum. $\quad \times 54,000$

FIG. 43 Amoeboid trichomonad. $\times 4,000$

FIG. 44 Spherical trichomonad. $\times 4,000$

FIG. 45 Budding. $\times 4,000$

FIG. 45A (detail) Two costae can be seen where a bud is detaching. $\quad \times 13,500$

FIG. 46 Budding. Vesicles are visible in the bud. $\times 13,500$ 
thus resisting treatment, stresses the need for effective therapeutic methods directed against mixed infection.

\section{Summary}

Under the scanning electron microscope, the body surface of trichomonads appears ruffled and creased, with numerous crater-like depressions, which should probably be interpreted as the initial stage in the formation of digestive vacuoles or pinocytotic vesicles. Having contacted epithelial cells, trichomonads engulf them totally or partially. Various micro-organisms also become a prey of the protozoon. The different stages of phagocytosis are illustrated in electron micrographs.

Gonococci have been discovered in phagosomes of $T$. vaginalis. Usually their phagocytosis is not brought to completion and they survive within the trichomonads (endocytobiosis). This suggests that the agent of gonorrhoea may be maintained within trichomonads in cases of mixed infection.

In addition to morphological details described earlier, $T$. vaginalis has lattice-like and lamellar structures of uncertain function. Spherical forms are found usually in an unfavourable environment or as a result of budding.

\section{Key to the Figures}

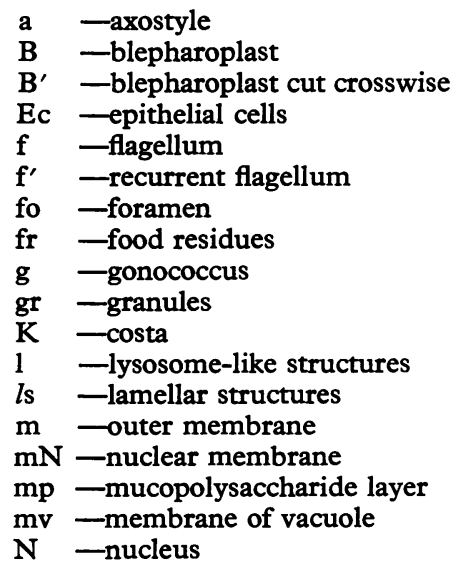

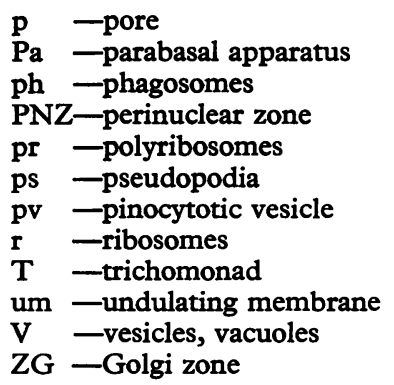

Note: Figs 1 to 4 show trichomonads under the scanning electron microscope; the other figures depict ultrathin sections as seen under the transmission electron microscope.

\section{References}

ANDerson, E., and Beams, H. W. (1959) F. Morphol., 104, 205

Hashimoto, M. (1964) f. fap. obstet. gynaec. Soc., 11, 162

Heath, J. P. (1974) Brit. F. vener. Dis., 50, 240 (letter)

HoNIGBERG, B. M., and KING, V. M. (1964) f. Parasitol., 50, 345

INOKI, S., and Hamada, Y. (1953) f. infect. Dis., 92, 1

LINDMARK, D. G., and MülLER, M. (1973) f. biol. Chem., 248, 7724

LudviK, J., Stokzosova, S., and Węglarska, B. (1961) Cs. Parasit., 8, 257

MÜLLER, M. (1973) F. Cell Biol., 57, 453

NÜRNBERGER, F., BARTUNEK, G., and SCHULTZE, M. (1974) Castellania, 2, 33

OvčinNIKov, N. M., and DelekToRskiJ, V. V. (1969) Akusherstvo $i$ Ginekologia, 45, No. 8, p. 10

,-- (1973) Vestn. derm. vener., No. 12, p. 48 (1974) 'Atlas of Electron Microscopy. Some Representatives of the Treponeme Genus, the Neisseria Genus and Trichomonads'. "Medicine", Moscow

$\longrightarrow,-$, and Kosmacheva, S. A. (1974) Brit. F. vener. Dis., 50, 22

Panaitescu, D., Voiculescu, R., and Ionescu, M. D. (1971) Arch. Roum. Path. exp. Microbiol., 30, 87

Perju, A., and Petrea, I. (1963) Derm.-vener. (Buc.), 8, 403

Smith, B. F., and Stewart, B. T. (1966) Exp. Parasit. 19,52 